\title{
The powerful ideas of making: building beyond the curriculum
}

\author{
Nathan HolbertiD
}

Correspondence:

holbert@tc.columbia.edu Department of Mathematics,

Science, and Technology, Teachers College, Columbia University, 525

West 120th Street, Box 08, New

York, NY 10027-6696, USA

\begin{abstract}
In this paper, rather than consider how fabrication technologies and maker activities can be directly matched to existing standards or allow for more efficient content coverage, I position making as a network of powerful ideas and perspectives that are highly connected to other ideas, personal and syntonic to the learner, and are immediately useful for solving problems of personal importance. Furthermore, I argue that creating learning environments where learners encounter and take ownership of these powerful ideas requires instructors, coaches, administrators, and designers that are committed to creating space for the learner to make meaningful choices, to tinker and explore, and to collaborate. Bots for Tots, a project that engages children in making toys for members of their community, is briefly described to highlight the affordances and challenges of implementing design features that focus on engaging learners with powerful ideas.
\end{abstract}

Keywords: Constructionism, Making, Fabrication, Powerful ideas, Design

\section{Background}

While the "maker movement" has existed for a decade since the first Maker Faire in 2006, bringing digital fabrication and construction in the form of maker spaces and fabrication labs to schools and into the classroom is a relatively new phenomenon. As scholars, educators, and funders begin to explore the potential, and push for the inclusion of making in the formal education experience, there is a question of the value of these activities. Will the use of high tech equipment such as 3D printers, laser engravers, and microcontrollers improve students' understanding of content traditionally taught in science and math classrooms? Will these activities lead to a greater interest in STEM-related field and the acquisition of "21st century skills?" Or are these "making" activities simply about engagement?

In the current measurement-centric culture of education, the teaching profession too often becomes an exercise of checking off boxes from a list of standards or curriculum. Enthusiastic teachers and administrators may be willing to try something new, but the complex system of national and state standards, assessments, discrete content domains, bell schedules, funding policies, etc. ensures an equilibrium centered on content coverage. While learners engaged in making and construction will likely encounter school sanctioned content or could acquire desirable skills, a tally of marked checkboxes is a poor measure of the value of these activities.

(c) The Author(s). 2016 Open Access This article is distributed under the terms of the Creative Commons Attribution 4.0 International License (http://creativecommons.org/licenses/by/4.0/), which permits unrestricted use, distribution, and reproduction in any medium, provided you give appropriate credit to the original author(s) and the source, provide a link to the Creative Commons license, and indicate if changes were made. 
Making and construction is not about becoming proficient with a 3D printer, learning how to calculate resistance, or even about so-called 21st century skills. Making is about powerful ideas (Papert 1980). Making is a literacy-a way of reading the world as a collection of resources and materials to be composed, repurposed, and rearranged. Making is "what if?" and "why not?"-of taking responsibility for challenges and obstacles faced by oneself and one's community and enacting solutions. In this paper, I will reposition making as a network of powerful ideas and perspectives that enable action, rather than a set of activities and technologies. I will then describe three features of powerful ideas, aligning each to practices and mindsets common in maker spaces and fabrication labs. Finally, I will provide a set of recommendations for designing contexts and activities that put students in contact with these powerful ideas and illustrate these recommendations by describing the Bots for Tots project.

\section{Powerful ideas}

When we see a list of content to be covered or standards to enact, it is easy to assume each carries the same weight and value. And yet, in reality, some ideas on these lists are more important than others. Some ideas are simply more powerful-they provide insight into a large variety of other concepts or theories, they are more intuitive, and they are more useful! In his book, Mindstorms: Children, Computers, and Powerful Ideas, Papert (1980) argued that construction, and more specifically construction with digital tools and technologies, has a unique ability to bring children in connection with powerful ideas such as calculus, algorithmic thinking, and Newtonian mechanics that were previously inaccessible. But what makes an idea powerful, and why is construction an effective means of encountering these ideas? Papert (2000) suggested that powerful ideas are (1) highly connected to other ideas, (2) are personal and syntonic to the learner, and (3) are ideas that are immediately useful for solving problems of personal importance.

Powerful ideas are central hubs in a vast network of knowledge-they are connectors that not only explain many different phenomena but also provide an entry point into a whole host of other concepts or principles. Ideas such as the particulate nature of matter, recursion, and the attraction and repulsion of chargers are powerful because they are fundamental to our understanding of the world around us and underlie concepts and principles in a variety of domains. Powerful ideas are about diversity and growth-about opening one's eyes up to new ideas, explanations, experiences, and perspectives. Papert (1980) argued that powerful ideas themselves are the most powerful of powerful ideas (p. 76)!

Because powerful ideas exist in a network of knowledge, rather than a list of checkboxes (Blikstein 2012), the notions of "subject" or "domain" simply do not apply. Construction and fabrication brings this cross-domain nature of powerful ideas to the forefront. Embedding computation in fashion with a Lilypad Arduino (Buechley et al. 2008; Kafai et al. 2010); controlling a video game character with bananas, clay, and a Makey Makey (Davis et al. 2013; Millner 2010); programming a soccer-playing robot to score goals (Berland 2016; Berland et al. 2013); or making a mechanical wooden roller coaster (Blikstein 2013) each extend across traditional class subjects and engage learners with powerful ideas such as electricity flow, algorithmic thinking, and the conservation of energy. Furthermore, such activities connect hobbies explored 
informally with topics typically reserved for the classroom and can reach across gender and cultural boundaries inherent in some materials, contexts, and domains (Buechley and Perner-Wilson 2012; Kafai and Burke 2014; Holbert 2016).

Powerful ideas are personal. Powerful ideas emerge from our own tinkering and exploring rather than as a set of principles passed down from expert to novice. Complex and nuanced explanations of how we tuned voltage and resistance to automatically turn on a homemade nightlight when it is dark, or the way in which we passed variables in code to make a video game character jump higher when running, are personal and powerful because we made them work-because they were our solutions, not pre-made programs we simply enacted. Rather than rely upon ordained "experts" to provide explanations of how things work, making situates the builder-whether the hobbyist, the seamstress, or the mechanic-as the expert and reveals this work to be serious, valuable, and highly connected to the formal and real practices of the scientist and engineer (Blikstein 2013; Halverson and Sheridan 2014). Because powerful ideas are encountered through personal construction, they are more likely to connect with our daily experiences, our understanding of how our own body moves through the world, and our intuitions. This intimate connection with ideas alters their accessibility democratizing these powerful ideas once thought to require years of formal instruction (Wilensky and Papert 2010).

Finally, powerful ideas are about action-they are about use and productivity. Powerful ideas are powerful because they help us achieve goals that matter to us. They provide us with the cognitive tools or physical skills to explain the world around us and to change that world to meet the needs of our communities and ourselves. The powerful ideas encountered in construction allow an incarcerated youth to design, build, and learn to play the guitar (Cavallo et al. 2004), fourth graders to create math video games for tutoring younger classmates (Harel and Papert 1990), and children in the poorest neighborhoods of Brazil to film a documentary for the community outlining the dangers and the safety concerns of illegal electrical connections (Blikstein 2008).

\section{Discussion}

\section{Designing to encounter powerful ideas}

While making and construction has as its heart the acquisition and exploration of powerful ideas, creating contexts and enacting activities where the learners encounter and take ownership of these ideas requires an epistemic commitment to knowledge as a constructed thing (rather than passed down or written onto the learner) and a disposition amenable to improvisation. In other words, powerful ideas do not come for free simply because students are using a 3D printer. It takes instructors, coaches, administrators, and designers that are committed to creating space for the learner to make meaningful choices, to tinker and explore, and to collaborate.

A common mistake in designing constructionist environments or activities is to define the learning goal too narrowly. When we develop curriculum or learning goals (or even research questions), one learns to be explicit-to narrowly define a target and to articulate that target in clear and measurable terms. While certainly an important and immensely useful planning practice in more traditional curriculum design, in a constructionist space, where the learner's personal interests and goals are paramount, we may not be able to fully predict the trajectory, or even the exact character of the 
learning that is to take place. The goal then should not be to define the specific content or precise parameters of acceptable products, but rather to clearly define the relationship between the available tools, technologies, and representations and the target interactions, experiences, and ideas (Holbert and Wilensky 2014; Kafai and Peppler 2014). In such a space, any meaningful choice made by the learner over the course of the construction will result in valuable experiences and personal insight.

Similarly, activity design should allow for freedom and exploration, even at the cost of occasional stumbling blocks, "wasted time", and seemingly pointless play. In schools where time is at a premium, it is reasonable to desire a finite time of focused and "productive" work. So while a teacher or administrator may want to allow her students to use the maker space, they may also prefer the experience to be scripted and highly orchestrated. But quick and simple activities that result in highly polished products may in fact be detrimental to putting learners in contact with powerful ideas (Blikstein 2013; Blikstein and Worsley 2015). Construction is not a linear and one-way path. When constructing, there are many false starts, moments of musing and experimentation, times of uncertainly, and a fair amount of backtracking. But it is in the mistakes, the restarts, and the tinkering where we often have the opportunity to reflect and make sense of encountered concepts (Berland 2016; Kapur 2008). It is in the play and exploration where the ideas become our own.

Finally, construction is a collaborative activity (Papert 1980). The myth of the programmer down in a basement or the maker in the garage working alone is oversubscribed. Making happens in communities whether they gather in a shared space or an online forum. Construction involves seeking help and providing support (Bruckman 2000) and sharing components and code to remix existing designs (Brennan et al. 2010). This spirit of openness not only prompts support and collaboration but also encourages the creation of "readable" artifacts so that they can be shared (Papert 1980). In schools, collaboration is a tricky concept. We are ok with having students work in small groups as long as everyone "pulls their weight" and produces wholly original work. But not all aspects of a construction project require the same amount of work, and likewise, why rebuilt something your neighbor has already created? Powerful ideas are not only found in the beginning of a project. In fact, powerful ideas are themselves a construction and may only become apparent when multiple borrowed pieces are brought together into something new.

\section{Bots for Tots}

In the previous section, I argue that construction activities that put learners in contact with powerful ideas require an open design that allows for learners to make meaningful and personal choices, flexibility and space for tinkering and exploration, and opportunities to share and collaborate. In this section, I briefly describe the Bots for Tots project to highlight the affordances and challenges of implementing these design features.

The Bots for Tots project tasks elementary children to design and build a "dream toy" for younger children in their community. Workshop sessions engage participants in interviewing stakeholders, brainstorming and critiquing, prototyping, and construction. In a recent implementation of the Bots for Tots project (see Holbert, 2016 for a detailed description), fourth grade students (ages 9-10) from an elementary school located in an urban Northeastern US city were invited to attend a free, 5-day "making 
workshop" with the explicit goal of designing and building toys for their school's prekindergarten (preK) class. Participants were divided into design teams and each assigned to two to five preK "clients." Teams interviewed their clients, asking them to describe a dream toy-a toy that they have always wanted and imagined, whether or not such a toy exists! Fourth grade design teams were then tasked with building these dream toys over the course of the next five design sessions.

An important feature of the Bots for Tots workshop was to leave the design space open and up to the preK client and fourth grade designer. Because design teams interviewed four to six preK children at once, multiple "dream toys" were described. Rather than restrict toy construction to a particular genre or available equipment, participants were free to create a toy in whatever way seemed most appropriate to meet the requirements of the client. All design teams chose to find a way to integrate the many ideas into the toy design and did so in innovative ways such as merging ideas into one toy-such as Tayla and Inez's "shopkins" plane car-or creating multiple objects that worked together-as was the case in Kelly, Raquel, and Kyle's toy that included a pony doll riding a skateboard. Furthermore, designs utilized diverse materials and technologies including laser cut acrylic, sewn fabrics, repurposed toy parts, sensors, speaker devices, and other electronic components. While this variety of materials and participant designs adds complexity to the planning and implementation of a maker workshop, it allowed participants to gain experience and expertise with ideas and practices personally relevant to their goals. So for example, while Tayla, Inez, and Juan gained valuable experience drafting and measuring components that would eventually be cut on the laser cutter, Kelly, Raquel, and Kyle wrestled with ratios and patterns while planning the design of a doll and its clothes.

Likewise, the design process and construction activities were not a linear process. Participants engaged in extensive brainstorming sessions to consider ways of merging proposed dream toys and to share ideas between projects. Paper and craft prototypes varied widely both between groups as well as between members of the same group. In some cases, participants even began constructing a toy only to discover a day or two into the process that their design had fatal flaws! While the large number of abandoned designs and false starts could be perceived as lost time and resources, these prototyping and debugging phases foreground necessary design considerations-such as the importance of units when engaging in measurement-and highlight the large space of design possibilities.

Finally, participants in the Bots for Tots workshop frequently shared and critiqued toy designs. As one group worked on a combination plane and car toy, another group decided that they too should include a car component to satisfy their preK client. However, rather than simply copy this idea, they converted the car to a skateboard to be used with their in-construction doll. Groups also offered advice and suggestions for one another's designs. For example, one team suggested that they needed to build a toy that combined a car and a plane. When discussing which materials to use when making the wings and wheels, a participant from another team suggested something "squishy" so that the toy would be more pleasant to hold. Another designer quickly spoke up stating, "I disagree that the wings should be squishy! Isn't it an airplane and is supposed to fly? So how's it going to fly if the wings are squishy!" This atmosphere of 
collaboration encouraged participants to continually improve of their own designs as well as to be invested in the work and designs of their colleagues resulting in not only shared ideas, but also shared expertise.

\section{Conclusions}

In this paper, I have argued for a renewed focus on powerful ideas rather than to use making and construction to simply motivate typical classroom activity or to deliver standardized content and skills. The value of the maker movement is not in learning to use a 3D printer or gaining ambiguous 21st century skills. Rather, it is an opportunity to create learning experiences that allow for meaningful choices, provide space for tinkering and exploration, and engage learners in productive collaboration.

The maker movement has been an exciting reinvigoration of Papert's constructionist call to action. The grassroots enthusiasm for fixing, improving, and repurposing existing objects offers an opportunity to connect people of varying education, background, economic status to powerful ideas that were previously only attainable to the "priestly few" (Wilensky and Papert 2010). Bringing digital fabrication and making to classrooms and schools provides the necessary infrastructure for empowering the learner to take control of his or her education. Putting construction in the center of the curriculum is not about throwing away the checklists or neglecting the standards. Rather construction and making allows us to infuse those lists with personal stories and histories, with meaning and communal values, and ideas that have the power to change the world around us.

\section{Competing interests}

The author declares that he/she has no competing interests.

Received: 23 August 2016 Accepted: 18 October 2016

Published online: 11 November 2016

\section{References}

Berland, M. (2016). Making, tinkering, and computational literacy. In K. Peppler, E. Halverson, \& Y. B. Kafai (Eds.), Makeology: Makers as Learners (Vol. 2, pp. 196-205). NYC: Routledge.

Berland, M., Martin, T., Benton, T., Petrick Smith, C., \& Davis, D. (2013). Using learning analytics to understand the learning pathways of novice programmers. Journal of the Learning Sciences, 22(4), 564-599. http://doi.org/10.1080/ 10508406.2013.836655.

Blikstein, P. (2008). Travels in Troy with Freire: technology as an agent of emancipation. In Freire and the Possible Dream. Rotterdam: Sense Publishers.

Blikstein, P. (2012). Constructionism, learning sciences, and the maker culture. Panel presented at Constructionism 2012. Athens, Greece.

Blikstein, P. (2013). Digital fabrication and "making" in education: the democratization of invention. In FabLabs: Of Machines, Makers and Inventors (pp. 1-21).

Blikstein, P., \& Worsley, M. (2015). Why the maker movement carries the seeds of its own failure, and how to avoid it. In E. Halverson, K..Peppler, \& Y. Kafai, Makeology. New York: Routledge.

Brennan, K., Monroy-Hernández, A., \& Resnick, M. (2010). Making projects, making friends: online community as catalyst for interactive media creation. New Directions for Youth Development, 2010(128), 75-83.

Bruckman, A. (2000). Situated support for learning: Storm's weekend with Rachael. The Journal for the Learning Sciences, 9, 329-372.

Buechley, L., Eisenberg, M., Catchen, J., \& Crockett, A. (2008). The LilyPad Arduino: using computational textiles to investigate engagement, aesthetics, and diversity in computer science education. In Proceedings of the S/GCHI conference on Human factors in computing systems (pp. 423-432). New York: ACM. https://doi.org/10.1145/1357054 1357123.

Buechley, L., \& Perner-Wilson, H. (2012). Crafting technology: reimagining the processes, materials, and cultures of electronics. In ACM Transactions on Computer-Human Interaction.

Cavallo, D., Papert, S., \& Stager, G. (2004). Climbing to Understanding: Lessons from an Experimental Learning Environment for Adjudicated Youth. In Proceedings of the 6th International Conference on Learning Sciences (pp. 113-120). Santa Monica, California: International Society of the Learning Sciences.

Davis, R., Kafai, Y., Vasudevan, V., \& Lee, E. (2013). The education arcade: crafting, remixing, and playing with controllers for scratch games. In Proceedings of the 12th International Conference on Interaction Design and Children (pp. 439-442). New York: ACM 
Halverson, E. R., \& Sheridan, K. (2014). The maker movement in education. Harvard Educational Review, 84(4), 495-504. Harel, I., \& Papert, S. (1990). Software design as a learning environment. Interactive Learning Environments, 1(1), 1-32. Holbert, N. (2016). Bots for Tots: building inclusive makerspaces by leveraging "ways of knowing". In Proceedings of the 2016 Conference on Interaction Design and Children. Manchester: ACM.

Holbert, N., \& Wilensky, U. (2014). Constructible authentic representations: designing video games that enable players to utilize knowledge developed in-game to reason about science. Technology, Knowledge and Learning, 19(1-2), 53-79.

Kapur, M. (2008). Productive failure. Cognition and Instruction, 26(3), 379-424. http://doi.org/10.1080/ 07370000802212669.

Kafai, Y. B., \& Burke, Q. (2014). Connected code: why children need to learn programming. Cambridge, MA: MIT Press. Kafai, Y. B., \& Peppler, K. A. (2014). Transparency reconsidered: creative, critical, and connected making with E-textiles. In M. Ratto, M. Boler, \& R. Deibert, DIY Citizenship: Critical Making and Social Media (pp. 179-188). Cambridge, MA: MIT Press.

Kafai, Y. B., Peppler, K. A., Burke, Q., Moore, M., \& Glosson, D. (2010). Fröbel's forgotten gift: textile construction kits as pathways into play, design and computation. In Proceedings of the 9th International Conference on Interaction Design and Children (pp. 214-217). New York: ACM. http://doi.org/10.1145/1810543.1810574.

Millner, A. D. (2010). Computer as chalk: cultivating and sustaining communities of youth as designers of tangible user interfaces (Thesis). Massachusetts Institute of Technology, Cambridge, MA

Papert, S. (1980). Mindstorms: children, computers and powerful ideas. New York: Basic Books.

Papert, S. (2000). What's the big idea? Toward a pedagogy of idea power. IBM Systems Journal, 39(3.4), 720-729.

Wilensky, U., \& Papert, S. (2010). Restructurations: reformulating knowledge disciplines through new representational forms. Paper presented at Constructionism 2010, Paris, France.

Submit your manuscript to a SpringerOpen ${ }^{\circ}$ journal and benefit from:

- Convenient online submission

- Rigorous peer review

- Immediate publication on acceptance

- Open access: articles freely available online

- High visibility within the field

- Retaining the copyright to your article

Submit your next manuscript at $>$ springeropen.com 